\title{
Fresh at Twenty: The Oral History of Mint Records
} Kaitlin Fontana

Toronto, Canada: ECW Press, 2011

ISBN: 9781770410046 (PB)

RRP: \$22.95 CAD

\author{
Brian Fauteux \\ University of Wisconsin-Madison, USA \\ brian.fauteux@gmail.com
}

For over twenty years, Vancouver-based Mint Records has been a prominent force in the circulation of Canadian and American West Coast music. In Fresh at Twenty: The Oral History of Mint Records, Kaitlin Fontana assembles an oral history of the first twenty years of Mint (1991-2011) using interviews with individuals who have been instrumental in both the culture and operation of the label. Fresh at Twenty is Fontana's first book, and she has previously written articles for SPIN, Rolling Stone and Exclaim!

In the book's introduction, Fontana evokes a mythical Vancouver that "properly began when the then actually alternative local paper the Georgia Straight published its punk issue in 1977" with D.O.A.'s Joey Shithead on the cover (ix). "There was a definite punk period in Vancouver, which this book is not about," writes Fontana, "but from which the main parties in this book got ideas, which led to thoughts, which became actions" (ix). This energy carried over into the 1980s, influencing Mint's cofounders Randy Iwata and Bill Baker. Iwata and Baker are the two primary voices throughout this narrative, along with Fontana's which interjects and provides readers with added context and details that connect the various contributors' points. Examples of other individuals who participated in this oral history include Carl Newman and Kathryn Calder from the New Pornographers, Grant Lawrence from The Smugglers and Jenny Smyth from the Organ. Regretfully, a handful of former Mint artists declined to participate, including one of their most famous collaborators, Neko Case - although Case provided Fontana with a statement on her time spent with Mint, which is included in the book.

Fresh at Twenty is broken down into six parts of two to three chapters each, organized around major movements in West coast and Canadian popular music and significant moments in the label's history. For instance, the book's second part details the development of the Vancouver label in the shadow of the burgeoning grunge scene. In reference to Cub, a band responsible for garnering Mint a lot of attention in its early days, Fontana writes, "If Cobain and grunge were the '90s yin, then Cub's brand of pop was its yang, the echo of Sub Pop's Seattle to Mint's Vancouver" (77). Mint's connection to American West coast cities is also emphasized in the book's third part, which details the label's short-lived partnership with Lookout! Records in Berkeley, California.

The culture of the label is a recurring theme of the book, illustrating the ways in which Lookout! has often served as a launching-off point for independent bands that 
have later outgrown the means and resources of an independent Canadian label such as Mint. For example, Vancouver-based supergroup the New Pornographers formed after recording a song for a Mint Records compilation called Vancouver Special (2000). The band stayed with Mint for its first three releases, the last being Twin Cinema (2005), after which they moved exclusively to Matador. Fresh at Twenty highlights the tension that bands familiar with the culture of Mint have faced when making these business decisions. For instance Kurt Dahle, drummer for the New Pornographers, says "when the next record didn't do arms and legs better [than Twin Cinema] I was like, 'Oh, shit. We should have stayed on Mint'” (254).

Fresh at Twenty is not written with an academic audience in mind in that it is not grounded in prior theoretical, historical or ethnographic work, nor is the book reflexive about the process of conducting an oral history. Nevertheless, it contributes much useful information to the study of media industries and the production, distribution and performance of popular music. Fontana's book provides readers with a detailed glimpse at how one Canadian independent label has worked alongside musicians, promoters, journalists, college radio practitioners and music fans to help sustain the Vancouver music scene, locally and beyond. 